ISSN 1112-9867

\title{
ASSESSING CULTURAL INTELLIGENCE OF MALAYSIAN EXPATRIATES IN NETHERLANDS
}

\author{
S. B. Saihani ${ }^{1 *}$, W. A. Wan Razali ${ }^{2}$, Z. Mustapa ${ }^{2}$, and S. Sarbini ${ }^{2}$ \\ ${ }^{1}$ Institute of Business Excellence, Faculty of Business and Management, Universiti Teknologi \\ MARA, 40450 Shah Alam, Selangor, Malaysia \\ ${ }^{2}$ Faculty of Business and Management, Universiti Teknologi MARA, 40450 Shah Alam, \\ Selangor, Malaysia
}

Published online: 17 October 2017

\begin{abstract}
Organizations could suffer losses due to the ineffectiveness of the expatriates to comprehend their host culture. Previous studies suggest that the important measures to identify expatriate effectiveness primarily focus on the individual-level factors which are personality traits, gender, and prior international experience. Therefore, this study aims to investigate whether the Big Five personality model namely openness, conscientiousness, extraversion, agreeableness, and neuroticism have any influence on cultural intelligence. Using purposive sampling method, a total of 320 questionnaires were distributed via email to Malaysian expatriates in Hague, Netherlands. Results from multiple regression analysis indicate that personality traits of agreeableness, openness and extraversion are significant to Malaysian expatriate's cultural intelligence.
\end{abstract}

Keywords: big five personality; cultural intelligence; expatriate.

Author Correspondence, e-mail: shams887@salam.uitm.edu.my

doi: http://dx.doi.org/10.4314/jfas.v9i5s.61 


\section{INTRODUCTION}

The success of an international assignment generated many advantages to companies including access to new markets, aid in organizational coordination and control, and knowledge, skills, and technology proliferation [1] [2]. When multinational firms cross borders to conduct business abroad, these firms needs to ensure that their employees are competent and effective enough to meet international standards [3]. As a result, expatriates success or failure in an international assignment tend to rely on the effectiveness of the intercultural training as well as individual, work and family related factors [4] [5]. [2] also support the needs for expatriates to get involve with cross-cultural adjustment to ensure success to their international assignment. The important measures to identify expatriate effectiveness mainly focus on the individual-level factors such as personality traits, skill, gender, prior international experience, and local language fluency [6].

However, performing international assignments can be personally challenging to individuals that are not exposed to other culture and these obstacles may lead to poor job performance [3]. In addition, the selection process is one of the most crucial steps in chosing a candidate for international assignments. [7] asserts that underperforming expatriates could be detrimental to the organizations and individuals as they incurred cost in terms of relocation, compensation, and even termination. In a larger scale, companies can suffer losses in business opportunities, damage company's reputation, and weaken the relationship among customers, suppliers and government of host country.

Therefore, it is crucial to identify the gaps that remain in understanding the diverse factors affecting expatriate effectiveness [6]. Cultural intelligence signifies an essential intercultural capacity that is vital for expatriates working abroad. Furthermore, the study of the cultural intelligence concept is more meaningful if it is related to personality traits, which could lead to better job performance [2]. Without a doubt, the practice of hiring selection based upon the right personality traits are crucial given its absolute importance to the key decision makers. The main intention of this empirical study is to examine the influence of personality traits on cultural intelligence among the expatriates. The findings could potentially assist companies enroute to success in their international assignment. It is worth to note that, there are still gaps to be found even when there is an immense body of empirical research on cultural intelligence, 
and various variables have been recognized as contributing factor of success in international assignments. The authors believe that it would be fertile to discover these relationships. Five hypotheses were articulated in this study. Then, a methodology for analysis was delineated. These hypotheses were assessed empirically to determine the aptness of the model using questionnaire. In satisfying our investigation, a number of statistical analyses were conducted using SPSS Version 21.

\section{LITERATURE REVIEW}

One of the most demanded skill in international business is being culturally intelligent. This skill goes beyond international borders as it focuses thoroughly on the capability to adapt to individual from other diverse cultures and the ability to enhance the interconnectedness of people around the world [8].

\subsection{Cultural Intelligence}

[8] defines cultural intelligence as a theory in management and organizational psychology, postulating that understanding the effect of an individual's cultural practice on their behaviour is critical for effective business, and measuring an individual's ability to engage successfully in any environment or social setting. Culturally intelligent individuals are basically skillful and flexible about getting to know a culture, gathering more knowledge regarding the foreign culture from ongoing interactions, and have an initiative to be more sympathetic to the new culture and reshaping behaviours to make it appropriate for the new culture [9]. Cultural intelligence is established from the intelligence and emotional intelligence concept. Intelligence broadly can be defined as an individual's capability to understand and acknowledge about things, and to gain and use knowledge [10]. There are many factors that need to be taken into consideration when determining intelligence such as verbal fluency, comprehension, reasoning ability, abstract thinking and spatial and numerical reasoning [10]. When working in a team, especially involving foreign cultures, it is difficult to avoid conflicts [11]. Thus, cultural intelligence is the most suitable tool used in order to improve an individual's ability to connect with people from other cultures [12].

\subsection{Big Five Personality Traits}

Previously, there has been a rise in interest related to personality in organizations due to the 
focus given on the Big Five super ordinate factors of personality as its foundation [13] [11]. Most researchers recognized the fact that the Big Five model is crucial because it is one of the most reliable taxonomies in classifying personality traits for individul human characteristics and it has the ability to predict work behaviour either in domestic settings or in overseas assignment [13].

The personality trait of openness influence an individual's cultural intelligence, which is an ability to deal effectively with people from different cultural backgrounds [14] [15]. [13] point out that individual with a high sense of openness tend to nurture metacognitive strategies through thinking and interacting with people from different culture in their everyday lives. The openness to experience factor is a vital personality characteristics that is associated to a person's ability to work effectively in various cultural settings [15]. A person with conscientiousness has the characteristics of being dependable. These characteristics include being careful, thorough, responsible, organized, systematic, hard-working, achievement-oriented, ambitious, and persevering [16]. The conscientiousness factor can be regarded as the most reliable personality predictor of job performance across all types of task and occupations [15]. This is supported by [16] which similarly suggest that conscientiousness has the validity in measuring performance among all criterion types and occupational groups. In addition, individuals who are conscience tend to allocate more time and attention to planning, questioning cultural assumptions, observing the most appropriate cultural preferences, evaluating cultural norms before and during interactions and adjust mental models based on interactions with those from different cultures [13].

Recently, researchers have shown an increased interest in the extraversion factor as it is linked to the motivational and behavioural component of cultural intelligence. [15] found that individual who is highly extrovert has the tendency to be cheerful, enjoy interacting with people, comfortable when dealing with large groups, and seek excitement and stimulation. Extraversion involves being sociable, gregarious, assertive, talkative, and active [16]. [13] concluded that individuals who are extrovert tend to be more flexible in their behaviours when faced with intercultural encounters. In addition, a large and growing body of literature has investigated agreeableness in assessing a person's interpersonal orientation [15]. Agreeableness is a type of behaviour which include being curious, flexible, trusting, 
good-natured, forgiving, soft-hearted, and tolerant [16] [13]. In other word, an individual who does not embrace the agreeableness factor has the tendency to be cold, oppositional, hostile, and antagonistic in their behaviours and this could be problematic for a person who has to deal with various cultures [13]. The final personality traits called neuroticism refers to characteristics that include unnecessary anxiety, pessimism, low confidence and penchants for negative emotions [17]. [18] suggests that expatriates high in neuroticism would struggle in adjusting to a foreign culture than those low in neuroticism. They also found that neurotic inclinations, such as negative thinking, hesitation, and, worrying relate negatively to cross-cultural adjustment.

Based from the review of the literature, the following five hypotheses were generated. H1: There is a significant relationship between openness to experience with cultural intelligence.

H2: There is a significant relationship between conscientiousness with cultural intelligence.

H3: There is a significant relationship between extraversion with cultural intelligence.

H4: There is a significant relationship between agreeableness with cultural intelligence.

H5: There is a significant relationship between neuroticism with cultural intelligence.

\section{RESEARCH METHOD AND DATA ANALYSIS}

Both primary and secondary data were used in this exploratory and descriptive study. Data were acquired through journals and questionnaires. This study selected the non-probability sampling technique using purposive method. An email link was sent to the identified respondents. The use of the internet-based survey brought many advantages to the researchers to have access to a large population with a reduce cost and efficient survey administration [19] [20]. The population for the study comprised of Malaysia expatriates working in Hague, Netherlands. A total of 320 questionnaires were distributed to potential respondents referred by Malaysian embassy located in Hague, Netherlands and with only 150 were returned, thus yielding 46.9 percent return rate. 170 questionnaires were not returned and answered by the respondents due to lack of interest. Generally, response rate of 60 percent or better is preferred [21]. However, surveys with lower response rates produced more precise measurements than did surveys with higher response rates [22]. 
The bivariate frequency distribution is used in the findings and analysis to explain the demographic profiles of the respondents. The majority of respondents are male at $60.7 \%$ while the remaining $39.3 \%$ are female. In term of age, $36.7 \%$ of the respondents are between 30 and 39 years old, followed by $31.3 \%$ between 20 and 29 years old, $21.3 \%$ between 40 and 49 years old and $10.7 \%$ are above 50 years old. The majority of respondents are single at $62 \%$ and another $38 \%$ are married. Nearly $51.3 \%$ of the respondents are employed in the private sector and $48.7 \%$ are employed in the public sector. All of our sample showed a reasonable level of reliability $(\alpha>0.60)$ [23].

Two main methods were employed to determine the existence of multi-collinearity among independent variables in this study by calculating both Tolerance test and Variance Inflation Factor (VIF) [24]. The results of these analysis are presented in the Table I. As shown from the data, none of the Tolerance levels is $<$ or equal to 0.20 or 0.10 ; and none of the VIF values are between 5 and 10. Thus, the measures selected for assessing independent variables in this study do not reach levels indicate of multi-collinearity. Furthermore, the Durbin - Watson value of 1.913 in this analysis is between the acceptable ranges of between 1.5 and 2.5, and it shows that there was no auto correlation problems in the data used in this research. Thus, the measures selected for assessing independent variables in this study do not reach levels indicate of multi-collinearity.

Table 1. Test of collinearity

\begin{tabular}{|l|c|c|}
\hline Variable & Tolerance & VIF \\
\hline Openness & .380 & 2.632 \\
\hline Conscientiousness & .742 & 1.349 \\
\hline Extraversion & .806 & 1.241 \\
\hline Agreeableness & .748 & 1.337 \\
\hline Neuroticism & .420 & 2.379 \\
\hline
\end{tabular}

Five hypotheses were formulated and tested. The results are shown in the table below. 
Table 2. Hypotheses results

\begin{tabular}{|c|c|c|c|c|c|}
\hline & Hypotheses & $\begin{array}{l}\text { std. beta }(\beta) \\
\text { (Coefficient) }\end{array}$ & $\begin{array}{l}\text { std. } \\
\text { error }\end{array}$ & $P$ value & Decision \\
\hline$H 1$ : & $\begin{array}{l}\text { There is a significant } \\
\text { relationship between } \\
\text { openness to } \\
\text { experience with } \\
\text { cultural intelligence. }\end{array}$ & .243 & .077 & .023 & Supported \\
\hline H2: & $\begin{array}{l}\text { There is a significant } \\
\text { relationship between } \\
\text { conscientiousness with } \\
\text { cultural intelligence. }\end{array}$ & .027 & .072 & .724 & $\begin{array}{c}\text { Not } \\
\text { supported }\end{array}$ \\
\hline H3: & $\begin{array}{l}\text { There is a significant } \\
\text { relationship between } \\
\text { extraversion with } \\
\text { cultural intelligence. }\end{array}$ & .400 & .049 & .000 & Supported \\
\hline H4: & $\begin{array}{l}\text { There is a significant } \\
\text { relationship between } \\
\text { agreeableness with } \\
\text { cultural intelligence. }\end{array}$ & .251 & .071 & .001 & Supported \\
\hline H5: & $\begin{array}{l}\text { There is a significant } \\
\text { relationship between } \\
\text { neuroticism with } \\
\text { cultural intelligence. }\end{array}$ & -.184 & .066 & .069 & $\begin{array}{c}\text { Not } \\
\text { supported }\end{array}$ \\
\hline
\end{tabular}

The result explained in Table 2 represents the outcomes of a multiple regression analysis used to evaluate the strength of the proposed relationship. With $\mathrm{R}$ squared level of 0.39 , there are three significantly related variables that prevail, which are openness, extraversion and agreeableness. Their $\mathrm{p}$ value is at $95 \%$ confidence level. 


\section{DISCUSSION AND CONCLUSION}

Openness to experience is one of the important factors that influence cultural intelligence among expatriates. This is consistent with the findings founded by [15] that stated personality trait of openness has a positive influence to the cultural intelligence of Malaysian expatriates. This result is also supported by [25] that indicate openness to experience is important to function effectively in a culturally diverse setting. While [15] indicate that conscientiousness is one of the most relevant measures in culture intelligence, findings from [2] show the opposite. This can be due to the fact that the respondents in the study conducted by [15] was from western cultural setting. In addition, [13] indicate that extraversion has a strong relation with cultural intelligence especially towards the motivational and behavioural culture intelligence component. As individuals get more involved with the foreign environment and companions, they are more likely to be in tune with the new surroundings and this support the finding of this study the importance of extraversion among Malaysian expatriates to perform well in their international assignments. [13] further reiterate that agreeableness relates to the behavioural aspects of cultural intelligence. Individuals that possess this trait have the tendency to cooperate well in their everyday lives and they have a greater sense of adaptability and flexibility in dealing with people from another culture. However, individuals that are highly neurotic will less likely to develop positive attitudes towards their work [17]. Therefore, companies are most likely to select individuals who are emotionally stable in order to achieve the best outcomes.

\section{IMPLICATIONS OF THE STUDY}

Cultural intelligence can be developed over time. It is crucial for potential expatriates to self-reflect their true personalities and identify their strengths and weaknesses before taking international assignments. Furthermore, cultural intelligence is not something a person naturally possesses. It is enhanced through experience, knowledge, and having the right mindset in accepting the new cultural environment. In addition, everyone adapts to a new surrounding at a different pace. With the right approach, knowledge, experience and attitude, a person will be more prepared in overcoming various challenges when working with various culture. The findings in this study could benefits companies as well as expatriates in 
overcoming their shortcomings in their international assignments. It is recommended that for future research, other important model that influence cultural intelligence should be taken into account. There are certain aspects, other than personalities that have a major impact on cultural intelligence. For instance, the Global Leadership Competency (GLC) model can be used to measure cultural intelligence among expatriates. The GLC model believes that a higher level of global leadership is essential for functional excellence in a global environment.

\section{REFERENCES}

[1] Sarkiunaite I, Rocke D. The expatriate experience: The factors of international assignment success. Transformations in Business \& Economics, 2015, 14(1):20-47

[2] Kumar N, Che Rose R, and Sri Ramalu S. The effects of personality and cultural intelligence on international assignment effectiveness: A review. Journal of Social Sciences, 2008, 4(4):320-328.

[3] Caligiuri P, Tarique I. International assignee selection and cross cultural training and development. In I. Björkman \& G. Stahl (Eds.), Handbook of Research in IHRM. London: Edward Elgar Publishing, 2005, pp. 1-32

[4] Gupta R, Banerjee P, and Gaur J. Exploring the role of the spouse in expatriate failure: A grounded theory-based investigation of expatriate'spouse adjustment issues from India. The International Journal of Human Resource Management, 2012, 23(17):3559-3577

[5] Grundey D. Internationalisation and cross-cultural business environment: Modelling the training process of expatriates. Transformation in Business \& Economics, 2008, 7(2):114-129 [6] Subramaniam A, Ramalu I, Wei C C, and Rose R C. The effects of cultural intelligence on cross-cultural adjustment and job performance amongst expatriates in Malaysia. In International Journal of Business and Social Science, 2011, 2(9):59-71

[7] Ashamalla M H. International human resource management practices: The challenge of expatriation. Competitiveness Review: An International Business Journal, 1998, 8(2):54-65 [8] Etebarian A, Damirchi Q V, and Darban M Z. Cultural intelligence and managers achievement in Iranian cultural institutions. Arabian Journal of Business and Management Review, 2011, 1(4):55-60

[9] Thomas D C, Inkson K. People skills for global business: Cultural intelligence. San 
Francisco: Berrett-Koenler, 2003.

[10] Van den Bergh, R. Cultural intelligence: A comparison between managers in South Africa and the Netherlands. Unuiversity of Pretoria, Doctoral Dissertation, 2008

[11] Koh C, Joseph D, and Ang S. Cultural intelligence and collaborative work: Intercultural competencies in global technology work teams. In Proceedings of International Workshop on Intercultural Collaboration, 2009, 261-264

[12] Ramirez A R. Impact of cultural intelligence level on conflict resolution ability: A conceptual model and research proposal. Emerging Leadership Journeys, 2010, 3(1):42-56

[13] Ang S, Van Dyne L, and Koh C. Personality correlates of the four-factor model of cultural intelligence. Group \& Organization Management, 2006, 31(1):100-123

[14] Li M, Mobley W H, and Kelly A. Linking personality to cultural intelligence: An interactive effect of openness and agreeableness. Personality and Individual Differences, 2016, $89,105-110$

[15] Verghese T P, D'Netto B. Cultural intelligence and openness: Essential elements of effective global leadership. International Review of Business Research Papers, 2011, 7(1):191-200

[16] Evans E H. Expatriate success: Cultural intelligence and personality as predictors for cross-cultural adjustment. The University of Tennessee, Doctoral dissertation, 2012

[17] Lim Leung S, Bozionelos N. Five-factor model traits and the prototypical image of the effective leader in the Confucian culture. Employee Relations, 2004, 26(1):62-71

[18] Ward C, Leong C H, and Low M. Personality and sojourner adjustment: An exploration of the big five and the cultural fit proposition. Journal of Cross-Cultural Psychology, 2004, 35(2):137-151

[19] Dillman D A, Smyth J D, and Christian L M. Internet, mail, and mixed-mode surveys: The tailored design method. Hoboken, NJ: Wiley, 2009

[20] Kwak N, Radler B. A comparison between mail and web surveys: Response pattern, respondent profile, and data quality. Journal of Official Statistics, 2002, 18(2):257-273

[21] Davis C S, Gallardo H L, and Lachlan K L. Straight talk about communication research methods. Dubuque: Kendall Hunt Publishing Co, 2009

[22] Penny S V, Krosnick J A, Marquette J, and Curtin M. Public Opinion Quarterly, 1996, 
60(2):181-22

[23] Moore G C, Benbasat I. Development of an instrument to measure the perceptions of adopting an information technology innovation. Information systems research, 1991, 2(3):192-222

[24] Kleinbaum D G, Kupper L L, and Muller K E. Applied regression analysis and other multivariate method. PWS-Kent: Student's Partial Solutions Manual, 1988.

[25] Amiri A N, Moghimi S M, and Kazemi M. Studying the relationship between cultural intelligence and employees' performance. European Journal of Scientific Research, 2010, 42(3):418-427.

\section{How to cite this article:}

Saihani S B, Wan Razali W A, Mustapa Z, Sarbini S. Assessing cultural intelligence of malaysian expatriates in Netherlands. J. Fundam. Appl. Sci., 2017, 9(5S), 857-867. 